Article

\title{
Ultrafine-Grained Austenitic Stainless Steels X4CrNi18-12 and X8CrMnNi19-6-3 Produced by Accumulative Roll Bonding
}

\author{
Mathis Ruppert *, Lisa Patricia Freund, Thomas Wenzl, Heinz Werner Höppel and \\ Mathias Göken
}

Department of Materials Science and Engineering, Institute I: General Materials Properties, Friedrich-Alexander Universität Erlangen-Nürnberg, Martensstr. 5, 91058 Erlangen, Germany; E-Mails: lisa.freund@fau.de (L.P.F.); thomas.wenzl@fau.de (T.W.); hwe.hoeppel@fau.de (H.W.H.); mathias.goeken@ww.uni-erlangen.de (M.G.)

* Author to whom correspondence should be addressed; E-Mail: mathis.ruppert@fau.de; Tel.: +49-9131-8527478; Fax: +49-9131-8527504.

Academic Editor: Hugo F. Lopez

Received: 30 March 2015 / Accepted: 4 May 2015 / Published: 7 May 2015

\begin{abstract}
Austenitic stainless steels X4CrNi18-12 and X8CrMnNi19-6-3 were processed by accumulative roll bonding (ARB). Both materials show an extremely high yield strength of $1.25 \mathrm{GPa}$ accompanied by a satisfactory elongation to failure of up to $14 \%$ and a positive strain rate sensitivity after two ARB cycles. The strain-hardening rate of the austenitic steels reveals a stabilization of the stress-strain behavior during tensile testing. Especially for X8CrMnNi19-6-3, which has an elevated manganese content of 6.7 wt.\%, necking is prevented up to comparatively high plastic strains. Microstructural investigations showed that the microstructure is separated into ultrafine-grained channel like areas and relatively larger grains where pronounced nano-twinning and martensite formation is observed.
\end{abstract}

Keywords: accumulative roll bonding (ARB); austenitic steel; ultrafine-grained microstructure; strength; nano-twinning; strain rate sensitivity 


\section{Introduction}

Accumulative roll bonding (ARB) [1] as a process of severe plastic deformation is one of the most effective methods for the production of bulk ultrafine-grained (UFG) materials with a median grain size smaller than $1 \mu \mathrm{m}$. The microstructural evolution during ARB is well described in literature, see for example [2-4] for details. The mechanical properties of those materials are frequently claimed to be favorable compared to their conventionally grained (CG) counterparts, as a good combination of high strength and satisfactory ductility can be achieved [5-7]. The enhanced ductility is often brought into connection with the enhanced strain rate sensitivity $[3,6,8,9]$ of those materials. Moreover, strain rate sensitivity is strongly related to an increased fraction of high angle boundaries [4], as they can act as sources and sinks for dislocations [3]. Although there are numerous publications on ARB available, only a couple of them are dealing with ARB-processing of steel-sheets. Among those, the majority concerns interstitial free bcc steels (IF-steels) with a rather low content of alloying elements, see for example [1,10-12]. However, there is very little literature available about ARB of austenitic steels, which will be focused on in the following. Kitahara et al. [13] investigated the martensite transformation of an ultrafine-grained Fe-28.5at.-\%Ni-alloy with single phase metastable austenite at room temperature. They performed the accumulative roll bonding process with sheets that were pre-heated at $500{ }^{\circ} \mathrm{C}$ for $600 \mathrm{~s}$ up to 5 cycles. However, each cycle was divided into two passes with a thickness reduction $<50 \%$. They achieved an ultrafine-grained microstructure with a mean grain size of $230 \mathrm{~nm}$ and a yield strength that was increased by a factor of 4.9 compared to the initial material. Moreover, they showed that the martensite transformation starting temperature decreases with the number of ARB cycles. Another study about ARB of austenitic steel was published by Jafarian et al. [14]. They investigated the microstructure and texture development in a Fe-24Ni-0.3C (wt.\%) austenitic steel up to 6 ARB-cycles and subsequent annealing. The processing was performed at $600{ }^{\circ} \mathrm{C}$. The texture was found to change from a copper orientation after 1 cycle towards a strong brass component after 6 cycles of ARB. Shen et al. [15] performed an accumulative cold rolling process with a thickness reduction of $17 \%$ each pass, using sheets of a commercial austenitic stainless steel $304 \mathrm{SS}$, which was pre-heated up to $400{ }^{\circ} \mathrm{C}$ prior to each pass. Due to various subsequent heat-treatments, they could achieve materials with different grain sizes. The tensile samples reached a yield strength of up to $1.8 \mathrm{GPa}$, yet rather small elongation to failure of about $6 \%$. Furthermore twinning and slip of partial dislocations were found to dominate plastic deformation in the ultrafine-grained state. Li et al. [16] processed sheets of an austenitic $36 \% \mathrm{Ni}$ (mass-\%) steel up to 6 cycles, with a pre-ARB heat-treatment at $500{ }^{\circ} \mathrm{C}$. They found a rather small grain size of $150 \mathrm{~nm}$ and a high misorientation concerning the high angle boundaries.

As no information is available in literature, this work is focused on the strain rate sensitivity of ARB-processed ultrafine-grained austenitic stainless steels. Moreover, the effect of ultrafine grains and pronounced nano-twinning on the mechanical properties of commercially available and technically relevant alloys was addressed. 


\section{Experimental Section}

Austenitic steels X4CrNi18-12 (1.4303) and X8CrMnNi19-6-3 (1.4376) were used as initial sheet materials for accumulative roll bonding. Due to the high Ni-content, the austenitic phase of $\mathrm{X} 4 \mathrm{CrNi18-12}$ is stabilized, which leads to a higher cold forming capability. This is desirable, as the material is severely strained during ARB-processing. The austenitic steel X8CrMnNi19-6-3 is a metastable one, which contains $6.7 \mathrm{wt} . \%$ of manganese. This induces twinning by plastic deformation, which might lead to satisfactory ductility. The material was delivered by Thyssen Krupp Nirosta $\mathrm{GmbH}$ and the chemical composition can be found in Table 1.

Table 1. Chemical compositions of the processed austenitic steels X4CrNi18-12 and X8CrMnNi19-6-3.

\begin{tabular}{cccccccccc}
\hline \multirow{2}{*}{ Alloy } & \multicolumn{10}{c}{ Composition in wt.\% } \\
\cline { 2 - 11 } & $\mathbf{C}$ & $\mathbf{S i}$ & Mn & $\mathbf{C r}$ & $\mathbf{T i}$ & $\mathbf{P}$ & $\mathbf{S}$ & Mo & Ni \\
\hline X4CrNi18-12 & $0-0.06$ & - & $0-2.0$ & $17.0-19.0$ & - & - & - & - & $11.0-13.0$ \\
X8CrMnNi19-6-3 & 0.025 & 0.46 & 6.76 & 17.43 & 0.001 & 0.029 & 0.0008 & 0.23 & 4.03 \\
\hline
\end{tabular}

The sheets of X4CrNi18-12 and X8CrMnNi19-6-3 had an initial geometry of $25 \times 150 \times 1 \mathrm{~mm}$ (width $\times$ length $\times$ thickness) and were processed up to three and two cycles of ARB, respectively. Henceforth, the number of performed ARB cycles is denoted by N0-N3. Hereby one cycle of ARB equals a v. Mises equivalent strain of 0.8 . During each cycle, the sheets were degreased in acetone and wire brushed with a rotating steel brush. Afterwards, the sheets were pre-heated in an electrical furnace for $5 \mathrm{~min}$ at $300{ }^{\circ} \mathrm{C}$ and finally roll bonded with a thickness reduction of $50 \%$. After each cycle, edge cracking was cut off and the sheets were prepared accordingly to the scheme described above before the next cycle. In order to determine the mechanical properties of the processed sheets, both Vickers hardness measurements and tensile testing were performed. Therefore, a hardness measurement unit Leco V-100A and an Instron 4505 universal testing machine (Hegewald \& Peschke MPT GmbH, Nossen, Germany) for uniaxial tensile testing were utilized. The hardness measurements were conducted at the sheet plane, the rolling plane and the transversal plane. Tensile testing was conducted in rolling direction at room temperature and at strain rates of $10^{-3} \mathrm{~s}^{-1}, 10^{-4} \mathrm{~s}^{-1}$ and $10^{-5} \mathrm{~s}^{-1}$ in order to determine the strain rate sensitivity. Moreover, microstructural characterization was done using a Zeiss Cross Beam 1540 EsB (Carl Zeiss AG, Oberkochen, Germany) scanning electron microscope in backscattered electron contrast at an acceleration voltage of $11 \mathrm{kV}$ and a working distance of 7-8 mm, as well as a Philips CM 200 transmission electron microscope operated at $200 \mathrm{kV}$ (FEI, Hillsboro, OR, USA).

\section{Results and Discussion}

In Figure 1, the results of the hardness measurements in sheet plane, rolling plane and transversal plane are shown for $\mathrm{X} 4 \mathrm{CrNi18}-12$ and for $\mathrm{X} 8 \mathrm{CrMnNi19}-6-3$. Generally an increase of the hardness with the number of ARB cycles can be observed. The largest increase is found for the sheet plane, which is due to the high friction between the sheets and the rolls. This leads to a large shear strain at the surface regions of the sheet [17] and, therefore, to a $15 \%$ higher hardness compared to the other 
planes. Moreover, the hardness of both alloys increases severely during the first cycle of ARB, but only slightly during subsequent cycles. While the hardness of X4CrNi18-12 increases rather constantly between one and three cycles, the hardness of X8CrMnNi19-6-3 already appears to saturate after two ARB cycles.

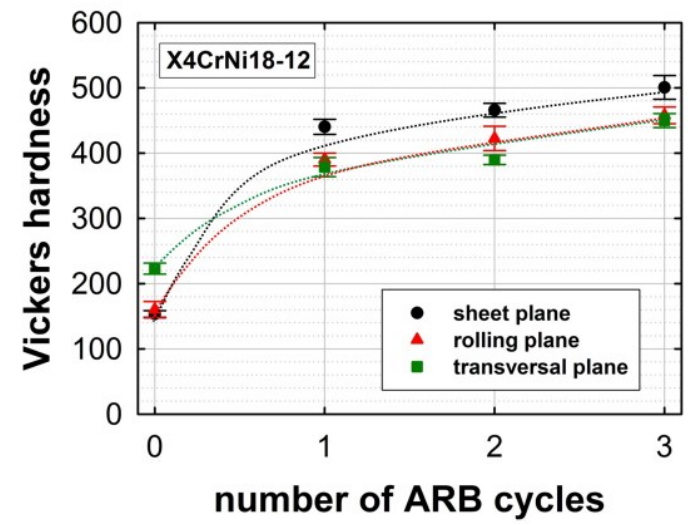

(a)

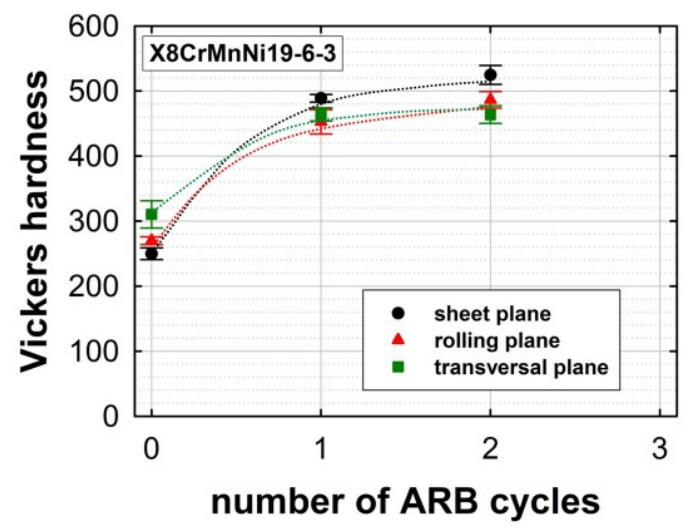

(b)

Figure 1. Vickers hardness measurements at the sheet, rolling and transversal planes of the samples after different cycles of ARB for (a) X4CrNi18-12 and (b) X8CrMnNi19-6-3.

The mechanical performance of both austenitic steels during tensile testing is shown in Figure 2 . The ultimate tensile strength (UTS) and the yield strength (YS) increase significantly during the first ARB cycle and the general trend is similar to the hardness measurements. That is to say, both steels reach a YS of around 1.25 GPa after N2 and N3, respectively. The highest increase in strength is found after the first cycle. Therefore, X4CrNi18-12 shows an increase of the UTS by a factor of 1.9 and an increase of the YS by a factor of 3.8. During subsequent ARB-cycles, the strength is further increased, although the relative increase is smaller. The total increase in yield strength compared to the initial material equals a factor of 4.7. The uniform elongation is reduced from $50.4 \%$ to $1.2 \%$, while the elongation to failure is reduced from $58 \%$ to $7.7 \%$. Similar behavior is found for X8CrMnNi19-6-3, which also shows a strong increase in strength and a strong decrease in ductility after the first ARB cycle. Thereby, the YS increases by a factor of 2.4. The reduction in ductility can be attributed to a decreased hardening rate after severe plastic deformation. Nevertheless, both materials show an excellent combination of strength and ductility. The ARB-processed X8CrMnNi19-6-3 especially performs very well and reaches an UTS between 1.3 and $1.5 \mathrm{GPa}$, while it maintains an elongation to failure between 10 and $14 \%$. Generally, the shape of the stress-strain curves changes after the first ARB cycle. While the N0 samples deform mainly uniformly during the tensile testing, the ARB-processed ones start necking at pretty low strains but show long post-necking deformation. This transition of tensile deformation behaviors in ultrafine-grained materials was discussed in detail for aluminum by $\mathrm{Yu}$ et al. [18]. Referring to this publication, tensile stress-strain curves can be categorized into four different characteristic types, in dependence of the grain size and the testing temperature. The N0-curves obtained in the present study a can be assigned to Type IV, which means that the curve shows continuous strain-hardening. This is typically observed in coarse-grained materials with a grain size larger than $4 \mu \mathrm{m}$. The stress-strain curves of the ARB processed 
X4CrNi18-12 can be assigned to Type II, which means that the curves exhibit a distinct yielding peak followed by strain-softening. Type II behavior is observed for grain sizes between $0.4 \mu \mathrm{m}$ and $1 \mu \mathrm{m}$. According to $\mathrm{Yu}$ et al. [18], the yielding peak is brought into connection with a lack of mobile dislocations, due to the large dislocation sink area provided by grain boundaries. This so-called yield-drop was also found for ultrafine-grained aluminum AA1100 and IF-steel [19], UFG Cu [20], UFG Ti [21] and also for cold-rolled high-manganese austenitic steel [22], which shows twinning induced plasticity. Concerning X8CrMnNi19-6-3, also a distinct yield point followed by strain softening can be observed. In Figure $2 d$, the true strain hardening rate is determined between the uniform elongation and the elongation to failure and plotted over the true plastic strain for both austenitic steels after N2. The curves were obtained by calculating the true stress strain curves (Figure 2c) from the engineering data and by determining the derivative of those curves. It has to be considered, that the actual cross-section of the tensile samples during tensile testing was not measured. However, the strain hardening curves can be compared qualitatively. It can be observed, that both materials initially show the same behavior up to $5 \%$ of plastic strain. That is to say, the strain hardening rate is reduced between the yield point and $3 \%$ of true plastic strain. Up to $5 \%$ the hardening rate for both alloys is increasing again. Afterwards, the strain-hardening rate of $\mathrm{X} 4 \mathrm{CrNi18}-12$ drastically decreases, while for X8CrMnNi19-6-3 the strain hardening rate increases until it suddenly drops as soon as the sample breaks. This is most likely due to failure because of ARB-related bonding defects. On the one hand, the stabilization of the stress-strain curves could be influenced by an enhanced strain rate sensitivity, which is typically observed for ultrafine-grained fcc metals. Thereby, thermally activated annihilation of dislocations is assumed to play a decisive roll and might lead to increased post-necking strains. On the other hand, both steels show a three-stage work hardening behavior, which is typical for materials with pronounced twinning activity and which is also found for high manganese TWIP (twinning induced plasticity) steels. It appears that the second stage is more distinct for $\mathrm{X} 8 \mathrm{CrMnNi19-6-3}$ compared to $\mathrm{X} 4 \mathrm{CrNi18}-12$. This might be due to the elevated manganese content, which leads to a higher twinning activity during tensile deformation that could stabilize the deformation behavior. The decreasing hardening rate after $5 \%$ of plastic strain, which is observed for $\mathrm{X} 4 \mathrm{CrNi18}-12$, might be attributed to a saturation in the amount of twinned grains. This saturation is not reached for $\mathrm{X} 8 \mathrm{CrMnNi19-6-3} \mathrm{during} \mathrm{plastic} \mathrm{straining.} \mathrm{However,} \mathrm{also} \mathrm{martensitic}$ transformation might contribute to the stabilization of the stress-strain curves. To gain more insight, the strain rate sensitivity and the twinning behavior of the materials were investigated.

The strain rate sensitivity (SRS) of the austenitic steels was determined from tensile testing experiments at strain rates of $10^{-3} \mathrm{~s}^{-1}, 10^{-4} \mathrm{~s}^{-1}$ and $10^{-5} \mathrm{~s}^{-1}$. SRS has to be determined under constant microstructural conditions. Thus, the determination of the SRS from tensile tests is rather crucial, as a microstructural stable condition is hardly achieved. In order to minimize this problem, all stress-strain curves were analyzed at maximum stress, which appears to be a good compromise between the evolution of the microstructure and the limitations of the onset of necking. Therefore, true stress-true strain diagrams were plotted and the maximum stress was evaluated from the different curves. Afterwards, the determined values where plotted over the corresponding strain rate according to $[23,24]$. Figure 3 reveals that in the initial N0 condition X4CrNi18-12 shows a small positive SRS of around 0.007 at room temperature, while the SRS of X8CrMnNi19-6-3 is around zero. After the first and the second ARB cycle, the SRS of $\mathrm{X} 4 \mathrm{CrNi18}-12$ is slightly decreased to around zero. 
However, it increases distinctly during the third ARB cycle to 0.017. A similar trend can be found for X8CrMnNi19-6-3, where the SRS remains around zero after the first cycle, but increases after the second cycle to 0.021 . The SRS after two cycles in the case of X8CrMnNi19-6-3 and after three cycles in the case of $\mathrm{X} 4 \mathrm{CrNi18-12}$ are in the range of SRS found for other ultrafine-grained fcc materials in literature $[6,9,25]$. Pronounced strain rate sensitivity is frequently brought into connection with an increased fraction of high angle boundaries, which is typically found in ultrafine-grained fcc metals, see for example [4]. Those high angle grain boundaries can act as sources and sinks for dislocations [3], which are able to stabilize the stress-strain behavior and eventually lead to a higher elongation to failure [6,25]. Consequently, Figure 2 reveals a higher elongation to failure for $\mathrm{X} 8 \mathrm{CrMnNi19-6-3}$ compared to $\mathrm{X} 4 \mathrm{CrNi18}-12$, as the strain rate sensitivity was determined to be higher. However, the SRS usually increases with the number of ARB cycles. Nevertheless, the SRS of $\mathrm{X} 4 \mathrm{CrNi18-12}$ is decreased after the first ARB cycle, which is a rather untypical behavior. In order to clarify more about this point, the microstructures of both alloys were investigated in detail by means of SEM and TEM.

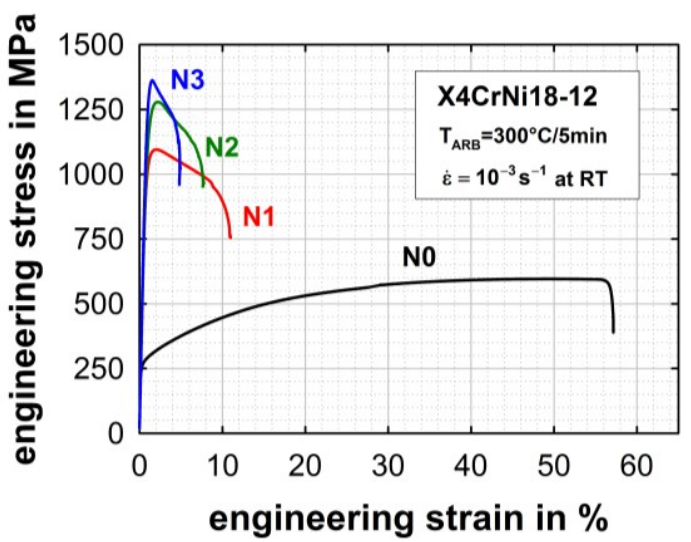

(a)

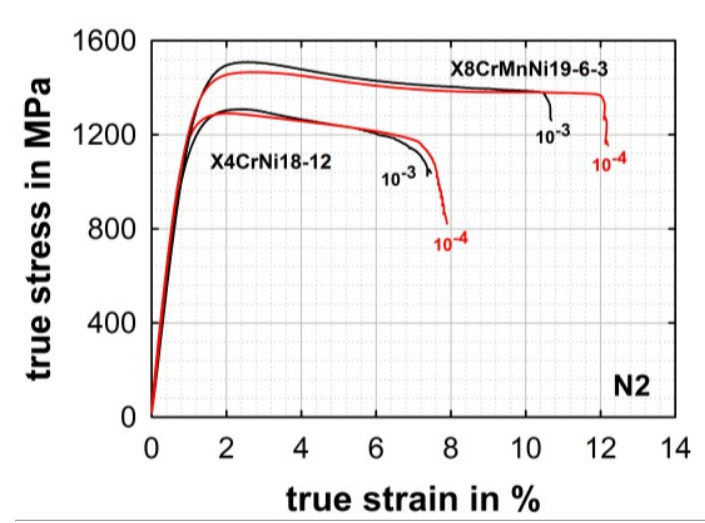

(c)

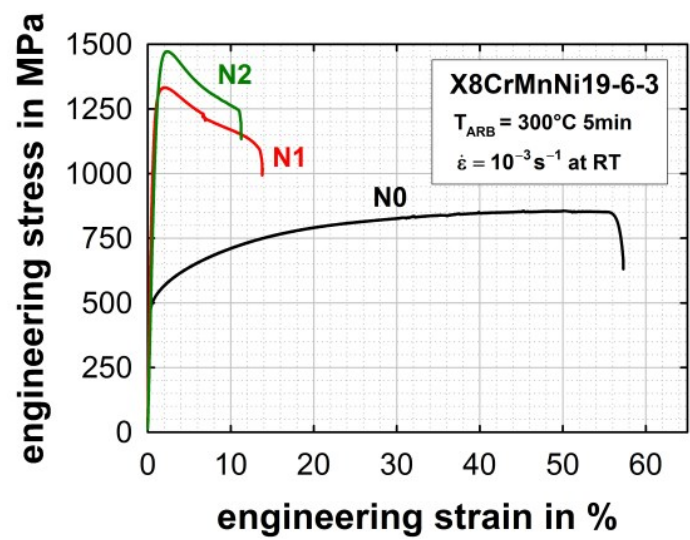

(b)

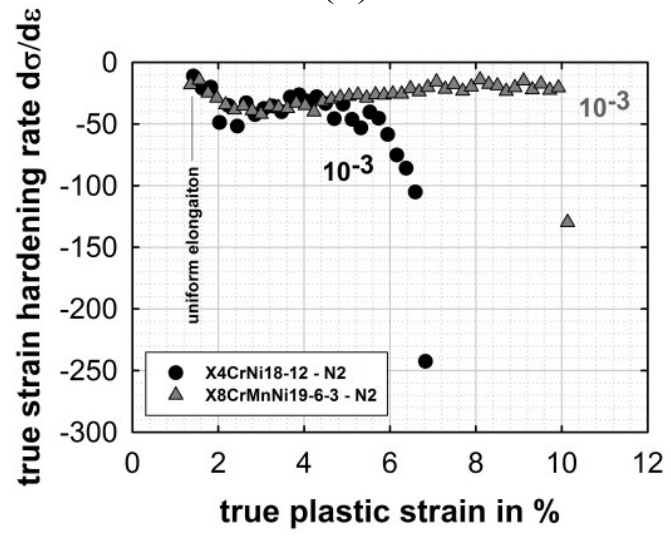

(d)

Figure 2. Engineering stress-strain curves at RT and a strain rate of $10^{-3} \mathrm{~s}^{-1}$ for (a) $\mathrm{X} 4 \mathrm{CrNi18-12}$ and (b) $\mathrm{X} 8 \mathrm{CrMnNi19-6-3.} \mathrm{(c)} \mathrm{Comparative} \mathrm{plot} \mathrm{of} \mathrm{true} \mathrm{stress-strain}$ curves of $\mathrm{X} 4 \mathrm{CrNi18-12}$ and $\mathrm{X} 8 \mathrm{CrMnNi19-6-3}$ at strain rates of $10^{-3} \mathrm{~s}^{-1}$ and $10^{-4} \mathrm{~s}^{-1}$. Stress-strain curves for $10^{-5} \mathrm{~s}^{-1}$ are omitted for reasons of clarity. (d) True strain hardening rate for X4CrNi18-12 and X8CrMnNi19-6-3 during tensile testing at a strain rate of $10^{-3} \mathrm{~s}^{-1}$ after $\mathrm{N} 2$ cycles of $\mathrm{ARB}$ between the uniform elongation and the elongation to failure. 


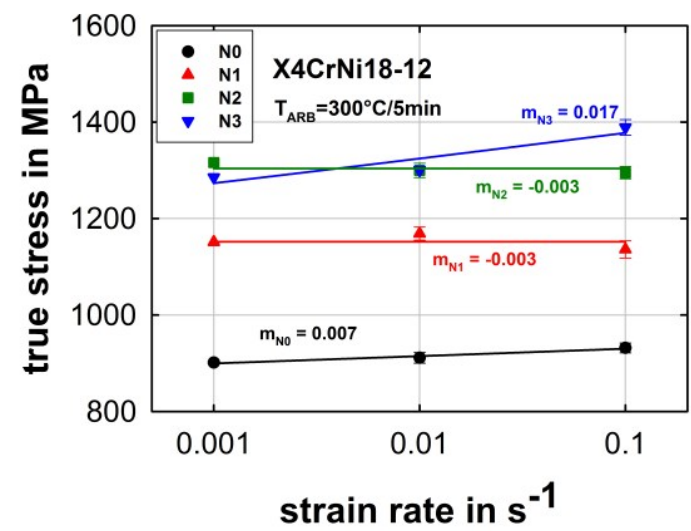

(a)

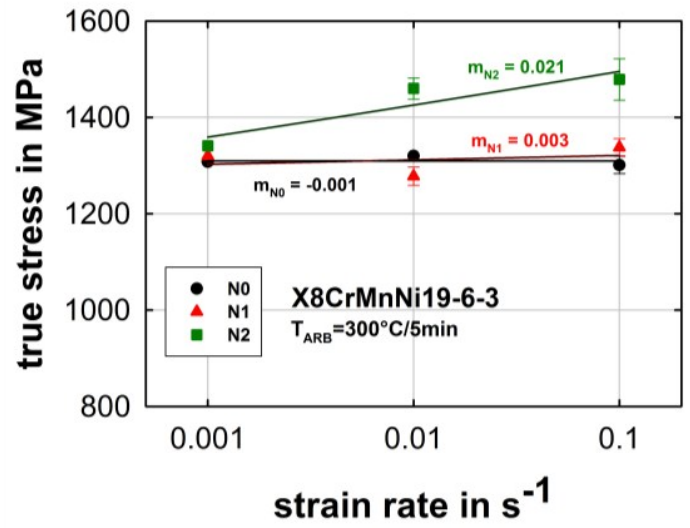

(b)

Figure 3. True maximum stress in $\mathrm{MPa}$ vs. strain rate for (a) $\mathrm{X} 4 \mathrm{CrNi18}-12$ and (b) $\mathrm{X} 8 \mathrm{CrMnNi19-6-3}$. The slope of the curves equals the strain rate sensitivity $\mathrm{m}_{\mathrm{N} x}$.

Concerning the stabilized austenitic steel X4CrNi18-12 in the initial N0 condition, which can be seen in Figure 4a, the grain size of the equiaxial austenite grains is found to be in the range between 15-30 $\mu \mathrm{m}$. Moreover, various annealing twins can be observed. The coarse grain structure leads to a high strain hardening capability and therefore to a high uniform elongation. Figure $4 \mathrm{~b}$ reveals that after one ARB-cycle $(\varepsilon=0.8)$ the grains appear highly deformed and pronounced mechanical twinning and martensite formation are clearly visible. Generally, the microstructure shows various types of microstructural features. On the one hand, large grains with a grain size clearly above $1 \mu \mathrm{m}$. These grains are filled up by nano-twins and martensite needles. On the other hand, shear band like regions were found, indicating highly localized plastic deformation with very small grain sizes in the UFG regime. With increasing number of ARB cycles, the fraction of the UFG area is extended and the grain size is further reduced far below $1 \mu \mathrm{m}$, see Figure 4c. Moreover, the heterogeneity of the microstructure related to the above described features decreases. Nevertheless, some of the ultrafine grains still contain nano-sized twins in the range of 5-20 nm, which could be observed in the TEM, see Figure 4d. According to Mangonon et al. [26], martensitic transformations in Fe-Cr-Ni alloys proceed in the sequence $\gamma(\mathrm{fcc}) \rightarrow \varepsilon$ (hcp) $\rightarrow \alpha^{\prime}$ (tetragonal-bcc). Thereby, $\alpha^{\prime}$ is preferably built at intersections of two $\varepsilon$ bands and near regions where $\varepsilon$ bands are adjacent to twins or grain boundaries. Furthermore, $\alpha^{\prime}$ first appears to be needle-shaped and becomes more lath-shaped during subsequent growth. Hereby, the growth of $\alpha$ ' leads to a reduction of the $\varepsilon$ phase. Shen et al. [27] found that both $\varepsilon$ and twins act as an intermediate phase during the transformation form $\gamma$-austenite to $\alpha$-martensite. Above a certain strain level, they observed that the twin density is decreasing, while the martensite density is further increasing. Huang et al. [28] performed detailed TEM-investigations on the nucleation mechanism of deformation-induced martensite in an austenitic steel under ECAP-deformation. They observed similar behavior as described above; however they could also find $\alpha^{\prime}$ nucleating at the intersection of two deformation twins and micro shear-bands. Accordingly, the diffraction patterns of those zones become rather complex (compare inset of Figure 5d). 


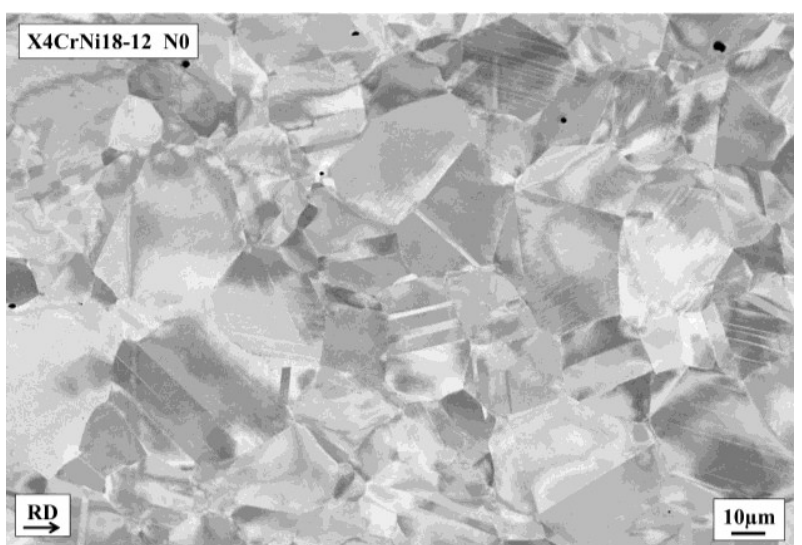

(a)

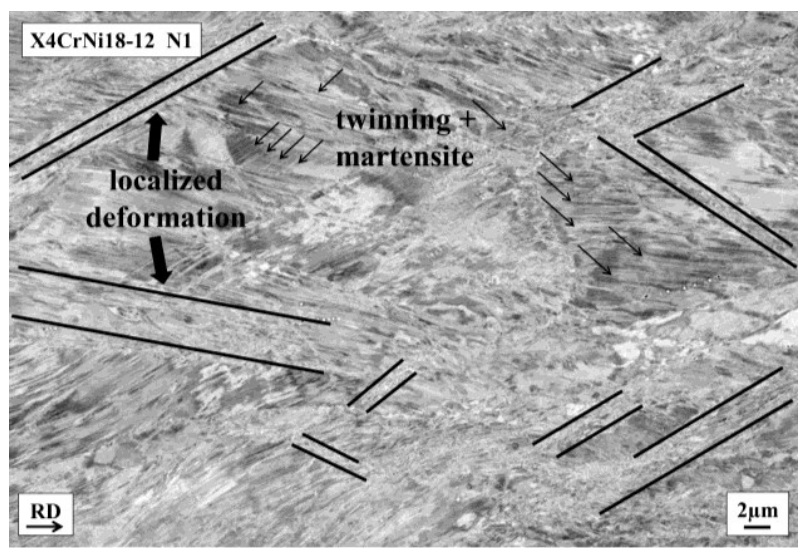

(b)

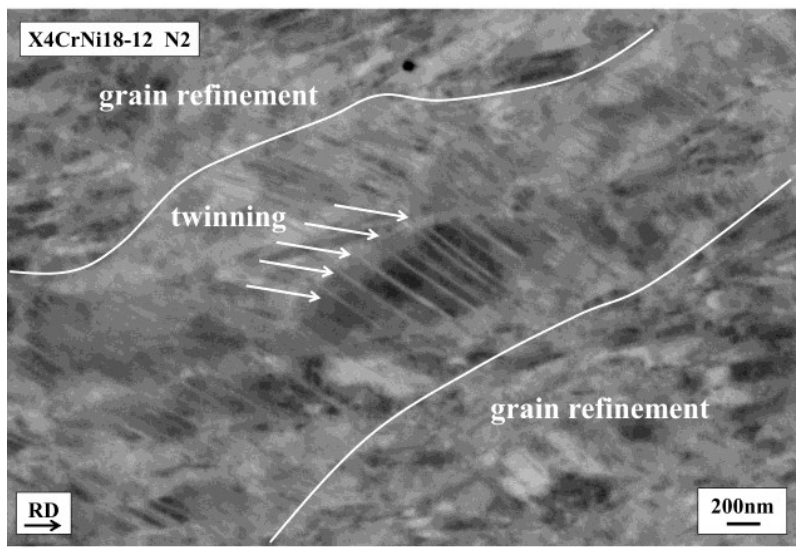

(c)

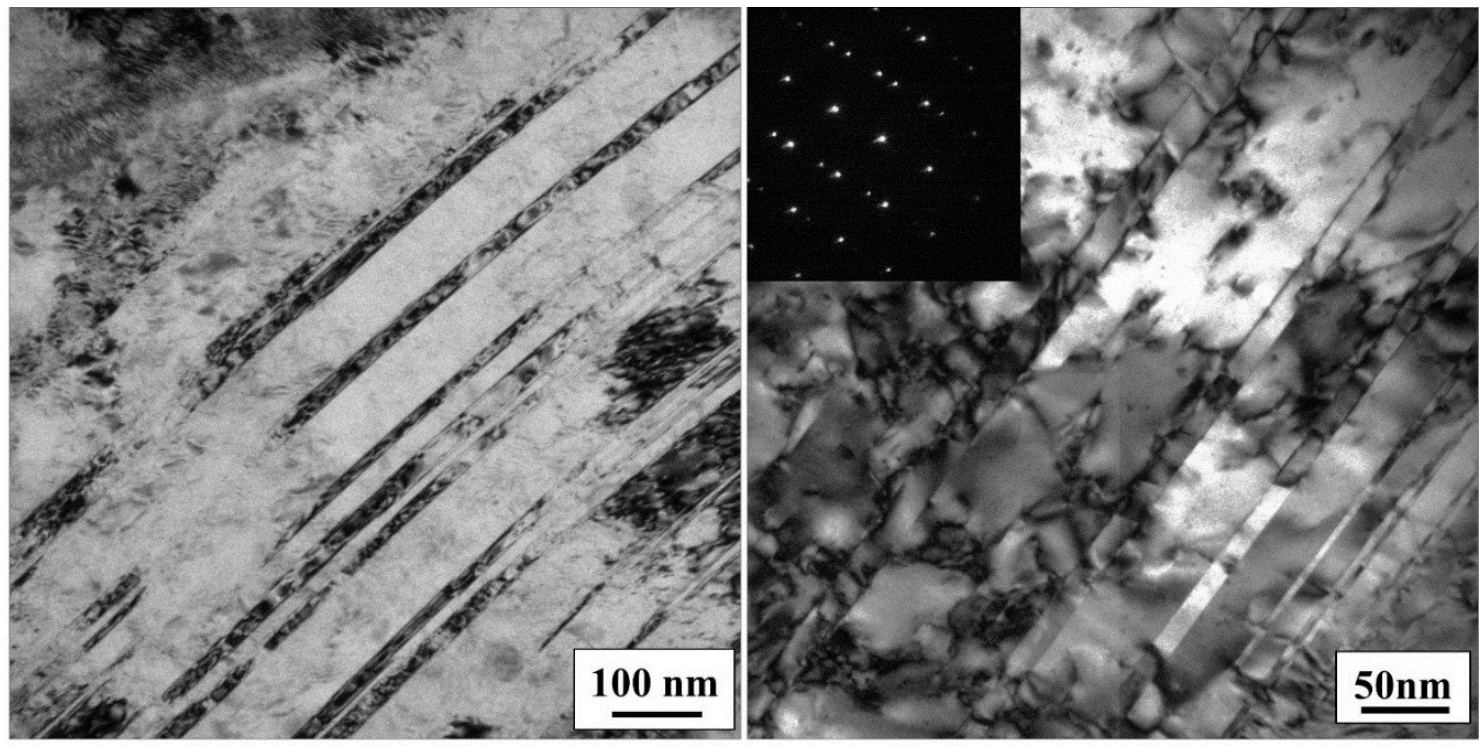

(d)

Figure 4. SEM micrographs of ARB-processed austenitic steel X4CrNi18-12 after (a) N0, (b) N1 and (c) N2. The arrows indicate areas where twins but also martensite were found. In (d) TEM captions of a highly twinned region with the corresponding diffraction pattern is shown after $\mathrm{N} 2$ cycles of ARB. 


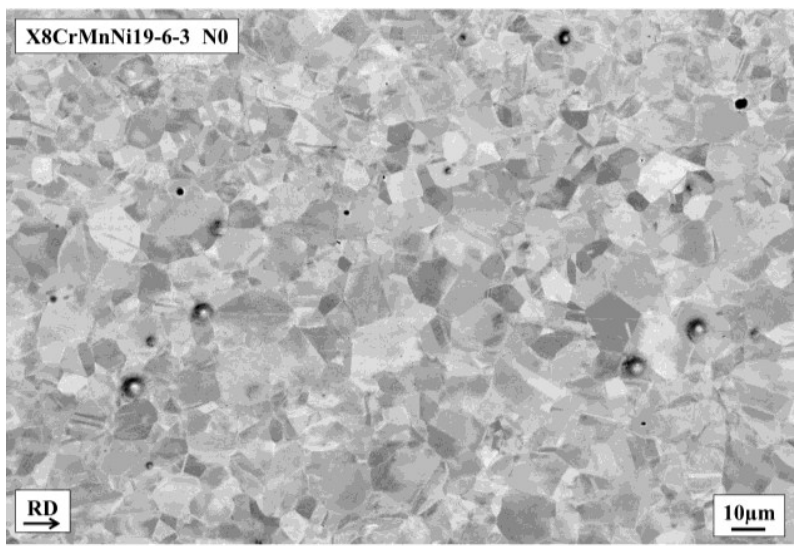

(a)

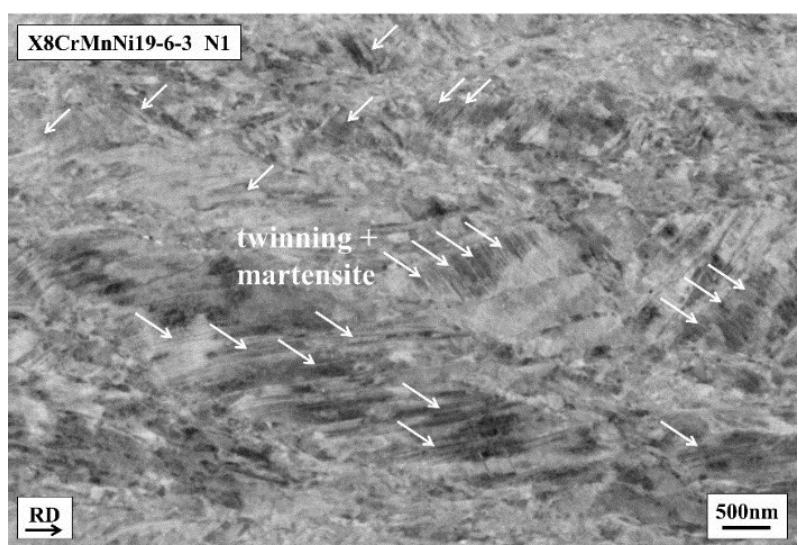

(b)

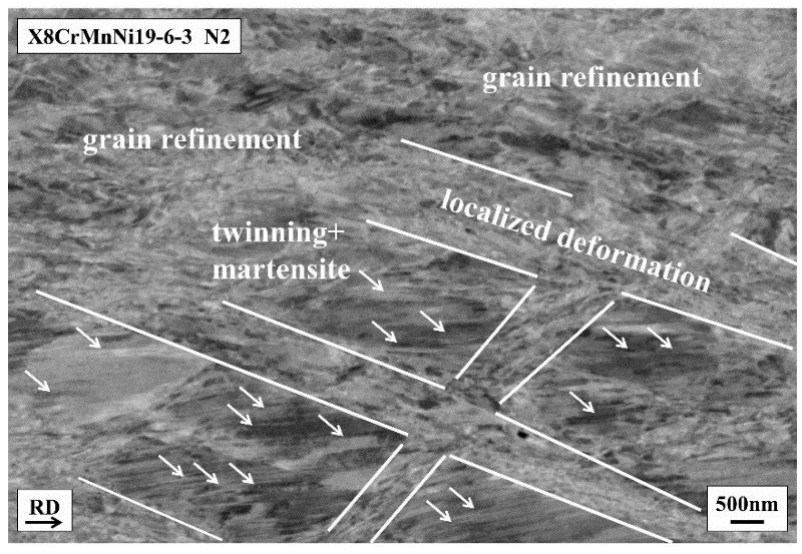

(c)
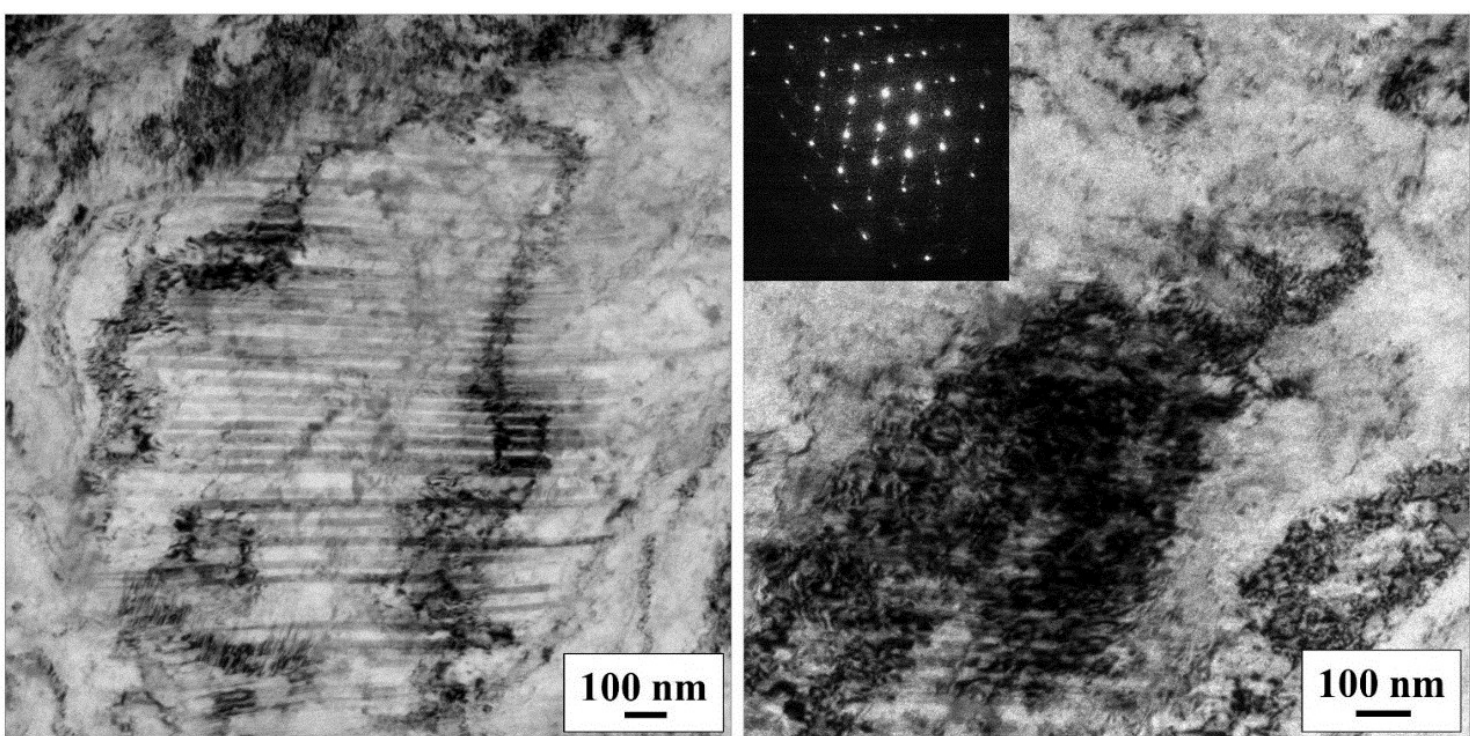

(d)

Figure 5. SEM micrographs of ARB-processed austenitic steel X8CrMnNi19-6-3 after (a) N0, (b) N1 and (c) N2 cycles. The arrows indicate areas where twins but also martensite was found. (d) TEM bright-field caption after N2 ARB-cycles and the corresponding diffraction pattern of this area. 
Generally, the microstructural evolution of the austenitic steel X8CrMnNi19-6-3 is quite similar to that of $\mathrm{X} 4 \mathrm{CrNi18}-12$. That is to say, $\mathrm{X} 8 \mathrm{CrMnNi19-6-3}$ also shows equiaxed coarse grains in the initial N0 condition. The grain size is about $10 \mu \mathrm{m}$, which is slightly smaller than that of X4CrNi18-12 and there is also a smaller amount of annealing twins, see Figure 5a. After the first ARB cycle, the microstructure already appears highly deformed, and both twinning and martensite are found in the whole microstructure, which can be seen in Figure 5b. Furthermore, some larger grains in the range between 0.5 and $1.5 \mu \mathrm{m}$ are found, which are rather randomly surrounded by very small grains. After the second ARB cycle, oval-shaped areas with a diameter of 2-5 $\mu \mathrm{m}$ are forming, see Figure 5c. Those areas are divided by zones of localized plastic deformation and very small grain sizes, which appear to be shear bands orientated $45^{\circ}$ to rolling direction. Moreover, the fraction of ultrafine-grained areas is clearly increased compared to the N1 condition. In TEM investigations $\gamma$-austenite, martensitic areas as well as twinning were found. Accordingly, in [28], the observed diffraction patterns were quite complex. In Figure 5d the diffraction pattern of such an area is representatively shown. Although indications for twinning and martensite could be found, the heavily deformed structures did not allow clear identification and separation of the different phases.

After the first ARB cycle, the microstructure of both alloys is dominated by larger grains containing mechanical twins and martensitic needles. As the fraction of ultrafine grains is rather small, twinning and martensitic transformation can be regarded as the dominating deformation mechanisms. Thus, the highly deformed microstructure contributes to the pronounced increase in strength. Twinning is also assumed to significantly contribute to plastic deformation during tensile testing, which stabilizes the stress-strain behavior. As a consequence of that, elongation to failure becomes relatively high, see Figure 2. Because of pronounced twinning after one ARB cycle and reduced interaction of dislocations with grain boundaries the strain rate sensitivity of both austenitic steels is approaching zero after the first ARB cycle, as shown in Figure 3. This appears to be in contrast to observations by Lu et al. [29], who report a positive effect of twins on the SRS in UFG Cu. Nevertheless, both the grain size and the twin thickness are in a much smaller regime in that study. Moreover. martensite formation found in this work might affect the SRS. As the fraction of ultrafine-grained regions is increasing again during subsequent $\mathrm{ARB}$ cycles and the twinned areas are reducing, the dislocation grain boundary interaction is enhanced and the strain rate sensitivity is also increasing again. This leads to a positive strain rate sensitivity, which is usually observed in many fcc metals. Mechanisms based on the thermally activated interaction of dislocations with grain boundaries, which might provide a good explanation for the observed increase in SRS, are given by Blum et al. [3] in terms of thermally activated annihilation of dislocations at grain boundaries or by Kato et al. [30] in terms of thermally activated dislocation depinning at grain boundaries. Moreover, grain boundary sliding cannot be completely neglected and might also contribute to the enhanced SRS to a certain extent. However, when ductility is regarded, the situation becomes more complex: On the one hand, with increasing number of ARB cycles, decreasing elongation to failure is observed as the twinning capability is further decreased and the fraction of martensitic areas becomes more pronounced. On the other hand, the SRS, which is known to positively affect ductility, see Figure 2c, is increased for both alloys. Consequently, the elongation to failure is still rather satisfactory. Therefore, it is assumed that the increased strain rate sensitivity, martensitic transformation as well as twinning appear to contribute to the good ductility during tensile testing. 


\section{Conclusions}

In the present study, commercially available austenitic steels $\mathrm{X} 4 \mathrm{CrNi18}-12$ and $\mathrm{X} 8 \mathrm{CrMnNi19-6-3}$ were processed by accumulative roll bonding at elevated temperatures. For both alloys, pronounced twinning and needles like martensite were found after the first ARB cycle. An increase in yield strength by a factor of 3.9 and 2.4, respectively, was found. During subsequent ARB cycles, the fraction of ultrafine-grained microstructure was clearly increased and a very high yield strength of 1.25 GPa was achieved. For X8CrMnNi19-6-3, the high strength was combined with a satisfactory ductility of more than $10 \%$. The ultrafine-grained regions appeared in channels, dividing coarser areas where pronounced twinning with twin size of 5-20 nm was found. Typical for ultrafine-grained fcc metals, positive strain rate sensitivity between 0.017 and 0.021 was revealed for both alloys, as soon as the fraction of ultrafine-grained regimes was increased. Strain rate sensitivity, twinning and martensitic transformation appear to contribute to the satisfactory ductility.

\section{Acknowledgments}

The authors would like to thank the German Research Council (DFG) for their financial support and the Cluster of Excellence "Engineering of Advanced Materials", which is funded within the framework of its "Excellence Initiative".

\section{Author Contributions}

Mathis Ruppert and Thomas Wenzl performed the mechanical characterization and the SEM investigations. Lisa Patricia Freund prepared the TEM images. Heinz Werner Höppel and Mathias Göken supervised the work and discussed the results with the other authors.

\section{Conflicts of Interest}

The authors declare no conflict of interest.

\section{References}

1. Saito, Y.; Tsuji, N.; Utsunomiya, H.; Sakai, T.; Hong, R.G. Ultra-fine grained bulk aluminum produced by accumulative roll-bonding (ARB) process. Scr. Mater. 1998, 39, 1221-1227.

2. Huang, X.; Tsuji, N.; Hansen, N.; Minamino, Y. Microstructural evolution during accumulative roll-bonding of commercial pure aluminum. Mater. Sci. Eng. A 2003, 340, 265-271.

3. Blum, W.; Zeng, X.H. A simple dislocation model of deformation resistance of ultrafine-grained materials explaining Hall-Petch strengthening and enhanced strain rate sensitivity. Acta Mater. 2009, 57, 1966-1974.

4. Hughes, D.A.; Hansen, N. High angle boundaries formed by grain subdivision mechanisms. Acta Mater. 1997, 45, 3871-3886.

5. Saito, Y.; Utsunomiya, H.; Tsuji, N.; Sakai, T. Novel ultra-high straining process for bulk materials-Development of the accumulative roll bonding (ARB) process. Acta Mater. 1999, 47, $579-583$. 
6. Höppel, H.W.; May, J.; Göken, M. Enhanced strength and ductility in ultrafine-grained aluminium produced by accumulative roll bonding. Adv. Eng. Mater. 2004, 6, 781-784.

7. Valiev, R.Z.; Alexandrov, I.V.; Zhu, Y.T.; Lowe, T.C. Paradox of strength and ductility in metals processed by severe plastic deformation. J. Mater. Res. 2002, 17, 5-8.

8. Wei, Q. Strain rate effects in the ultrafine grain and nanocrystalline regimes-influence on some responses. J. Mater. Sci. 2007, 42, 1709-1727.

9. May, J.; Höppel, H.W.; Göken, M. Strain rate sensitivity of ultrafine-grained aluminium processed by severe plastic deformation. Scr. Mater. 2005, 53, 189-194.

10. Tsuji, N.; Ueji, Y.; Minamino, Y. Nanoscale crystallographic analysis of ultrafine grained IF steel fabricated by ARB process. Scr. Mater. 2002, 47, 69-76.

11. Kamikawa, N.; Sakai, T.; Tsuji, N. Effect of redundant shear strain on microstructure and texture evolution during accumulative roll-bonding in ultralow carbon IF steel. Acta Mater. 2007, 55, 5873-5888.

12. Lee, S.-H.; Saito, Y.; Park, K.-T.; Shin, D.H. Microstructures and mechanical properties of ultra low carbon IF steel processed by accumulative roll bonding process. Mater. Trans. 2002, 43, $2320-2325$.

13. Kitahara, H.; Tsuji, N.; Minamino, Y. Martensite transformation from ultrafine grained austenite in Fe-28.5 at. \% Ni. Mater. Sci. Eng. A 2006, 438-440, 233-236.

14. Jafarian, H.; Eivani, A. Texture development and microstructure eolution in metastable austenitic steel processed by accumulative roll bonding and subsequent annealing. J. Mater. Sci. 2014, 49, 6570-6578.

15. Shen, Y.F.; Zhao, X.M.; Sun, X.; Wang, Y.D.; Zuo, L. Ultrahigh strength of ultrafine grained austenitic stainless steel induced by accumulative rolling and annealing. Scr. Mater. 2014, doi:10.1016/j.scriptamat.2014.05.001.

16. Li, B.; Tsuji, N.; Minamino, Y. Microstructural evolution in $36 \% \mathrm{Ni}$ austenitic steel during the ARB process. Mater. Sci. Forum 2006, 512, 73-78.

17. Lee, S.-H.; Saito, Y.; Tsuji, N.; Utsunomiya, H.; Sakai, T. Role of shear strain in ultragrain refinement by accumulative roll-bonding (ARB) process. Scr. Mater. 2002, 46, 281-285.

18. Yu, C.Y.; Kao, P.W.; Chang, C.P. Transition of tensile deformation behaviors in ultrafine-grained aluminum. Acta Mater. 2005, 53, 4019-4028.

19. Tsuji, N.; Ito, Y.; Saito, Y.; Minamino, Y. Strength and ductility of ultrafine grained aluminum and iron produced by ARB and annealing. Scr. Mater. 2002, 47, 893-899.

20. An, X.H.; Wu, S.D.; Zhang, Z.F.; Figueiredo, R.B.; Gao, N.; Langdon, T.G. Enhanced strength-ductility synergy in nanostructured $\mathrm{Cu}$ and $\mathrm{Cu}-\mathrm{Al}$ alloys processed by high-pressure torsion and subsequent annealing. Scr. Mater. 2012, 66, 227-230.

21. Li, Z.; Fu, L.; Fu, B.; Shan, A. Yield point elongation in fine-grained titanium. Mater. Lett. 2013, 96, 1-4.

22. Saha, R.; Ueji, R.; Tsuji, N. Fully recrystallized nanostructure fabricated without severe plastic deformation in high-Mn austenitic steel. Scr. Mater. 2013, 68, 813-816.

23. Hart, E.W. Theory of the tensile test. Acta Metall. 1967, 15, 351-355.

24. Ghosh, A.K. On the measurement of strain-rate sensitivity for deformation mechanism in conventional and ultra-fine grain alloys. Mater. Sci. Eng. A 2007, 463, 36-40. 
25. Höppel, H.W.; May, J.; Eisenlohr, P.; Göken, M. Strain-rate sensitivity of ultrafine-grained materials. Zeitschrift für Metallkunde 2005, 96, 566-571.

26. Mangonon, P.; Thomas, G. The martensite phases in 304 stainless steel. Metall. Trans. 1970, 1, 1577-1586.

27. Shen, Y.F.; Li, X.X.; Sun, X.; Wang, Y.D.; Zuo, L. Twinning and martensite in a 304 austenitic stainless steel. Mater. Sci. Eng. A 2012, 552, 514-522.

28. Huang, C.X.; Yang, G.; Gao, Y.L.; Wu, S.D.; Li, S.X. Investigation on the nucleation mechanism of deformation-induced martensite in an austenitic stainless steel under severe plastic deformation. J. Mater. Res. 2007, 22, 724-729.

29. Lu, K.; Lu, L.; Suresh, S. Strengthening materials by engineering coherent internal boundaries at the nanoscale. Science 2009, 324, 349-352.

30. Kato, M. Thermally activated dislocation depinning at a grain boundary in nanocrystalline and ultrafine-grained materials. Mater. Sci. Eng. A 2009, 516, 276-282.

(C) 2015 by the authors; licensee MDPI, Basel, Switzerland. This article is an open access article distributed under the terms and conditions of the Creative Commons Attribution license (http://creativecommons.org/licenses/by/4.0/). 